\title{
Comparative Study of the Physicochemical Characterization of Some Oils as Potential Feedstock for Biodiesel Production
}

\author{
Cynthia Nkolika Ibeto, ${ }^{1}$ Chukwuma Obiajulu Benedict Okoye, ${ }^{2}$ \\ and Akuzuo Uwaoma Ofoefule ${ }^{1}$ \\ ${ }^{1}$ Biomass Unit, National Centre for Energy Research and Development, University of Nigeria, Nsukka, Nigeria \\ ${ }^{2}$ Department of Pure and Industrial Chemistry, University of Nigeria, Nsukka, Nigeria
}

Correspondence should be addressed to Cynthia Nkolika Ibeto, cibeto@yahoo.com

Received 21 April 2012; Accepted 19 June 2012

Academic Editors: E. R. Bandala and F. E. Little

Copyright (C) 2012 Cynthia Nkolika Ibeto et al. This is an open access article distributed under the Creative Commons Attribution License, which permits unrestricted use, distribution, and reproduction in any medium, provided the original work is properly cited.

\begin{abstract}
Physicochemical properties of Cucurbita pepo, Brachystegia eurycoma, Cucumis melo, Luffa cylindrica, and Arachis hypogaea oils were studied to determine their potential as viable feedstock for biodiesel production. The nonedible oils were extracted by solvent extraction using n-hexane while the oil of Arachis hypogaea was procured. All the oils were characterized for specific gravity, pH, ash content, iodine value, acid value, saponification value, peroxide value, free fatty acid, flash point, kinematic viscosity, and refractive indices using standard methods. Cucurbita pepo seeds had very high oil content when compared to the others. Specific gravity and flash point of the oils were satisfactory. However, moisture content of some of the oils exceeded the stipulated ASTM standard for biodiesel production. Again, acid values of the nonedible oils were very high and exceeded the ASTM standard. They also exceeded the acid value of Arachis hypogaea oil except for Luffa cylindrica oil. Results indicate that the oils are potential biodiesel feedstocks. However, overall results indicate that the nonedible oils are not suitable for single-stage transesterification process to biodiesel but would be better suited for the two stage esterification and subsequent transesterification in order to obtain reasonable yields of the methyl esters.
\end{abstract}

\section{Introduction}

The rapidly growing global demand for petroleum products and the consequent depletion of the crude oil reserves in addition to adverse environmental concerns and unstable nature of the international market make imperative the need to explore alternative sources of fuel. Biodiesel is one of the promising renewable energy options already exploited by various countries. Categories of feedstocks as source of suitable oil for biodiesel production include seeds, nuts, leaves, wood, and even bark of trees. Nigeria is very well endowed with various edible and nonedible oils.

As a result of the extensive demands of oil for consumption and industrial uses, analyses of many oils have been carried out. The extraction and use of vegetable oils has for centuries played an important role in the manufacture of a large number of industrial products and food items [1] and also in biodiesel production. Certain edible oils such as cottonseed and safflower can be used as raw materials for biodiesel production. Some of the nonedible oils such as mahua, castor, neem (Azadirachta indica) , rice bran, linseed, Karanja (Pongamia pinnata), and jatropha (Jatropha curcas) have also be used [2]. However availability of these raw materials varies. This requires the search for new sources of novel oils. Several plants are now growing, not only for food and fodder but also for striking range of products with industrial applications [3].

Brachystegia eurycoma is an economically valuable tree crop mostly grown in the tropical rain forest of West Africa. Its uses range from food to medicine [4]. Sponge-gourds, the fruit of Luffa cylindrica, are widely used throughout the world. It is an annual climbing crop which produces fruit containing fibrous vascular system. It is a summer season vegetable [5]. Melon (Cucumis melo L.) is a commercially 
important fruit crop that is cultivated worldwide [6]. It is also an important summer vegetable crop especially in the rice fallows of Kerala [7]. Culture and use of cucurbits or squashes (Cucurbita pepo) have been traced to more than 10000 years ago [8]. The oils of Cucurbita Pepo, Brachystegia eurycoma, Cucumis melo, and Luffa cylindrica seeds are generally known as nonedible oils even though some of the seeds are consumed sparingly in some localities, while that of Arachis hypogaea are exported on a large scale as edible oil.

The chemical composition of the oil extract consequently gives a qualitative identification of oils and is a very important area in the selective application guide for the commercialization and utility of oil products. Fats and oils are also very important indigenous raw materials for many edibles and nonedible purposes [9]. The colours of vegetable and animal oils are usually transferred to the biodiesel made from them and so are other properties. Therefore, properties of the biodiesel greatly depend on that of the vegetable oil used for it [10].

This study was therefore undertaken to characterize oils extracted from Cucurbita pepo, Brachystegia eurycoma, Cucumis melo, and Luffa cylidrica seeds and compare their quality with Arachis hypogaea oil, an edible one known to be suitable for biodiesel production.

\section{Experimental}

This study was carried out in the National Centre for Energy Research and Development, University of Nigeria Nsukka in June, 2011. Materials used were specific gravity bottle, Hanna pH meter model No. 02895, oven (BTOV 1423), Vecstar furnace LF3, Ferranti portable viscometer model VL, Abbe refractometer, and semiautomatic Cleveland flash point tester. The seeds of Cucurbita pepo, Brachystegia eurycoma, Cucumis melo, and Luffa cylidrica were harvested from a farm in Nsukka, Enugu State, and separated from foreign materials and dirt. The seeds were dehulled mechanically to enable separation of seed coat and the testa. They were then sun-dried in the open for up to four days until the seed coat split and then the cotyledon was shredded. The seed coat was separated from the cotyledon by air blowing. A fuel operated grinding machine was used to crush the dried dehulled seed to coarse form.

2.1. Oil Extraction. The coarse meal from the seeds was subjected individually to solvent extraction for $5 \mathrm{~h}$ with nhexane at $55-60^{\circ} \mathrm{C}$ using Soxhlet extraction method. The oil solutions were filtered using a Büchner funnel and then subjected to distillation using rotary evaporator. The oils were weighed and put into well-closed containers. At the end of the extractions, the resulting mixtures containing the oils were heated to recover solvent from the oil [11]. However, the peanut oil used for this study was purchased from the market.

2.2. Physicochemical Analysis. The percentage (\%) yields of the nonedible oils were calculated. Odour, colour, and physical state of the oils were estimated by sensory evaluation. They were characterized for specific gravity using specific gravity bottle, $\mathrm{pH}$ were determined using a Hanna pH meter model no. 02895, moisture content by the oven dry method, ash content by heating to dryness in furnace, kinematic viscosity using a viscometer, refractive index using Abbe refractometer, and flash point using the semiautomatic Cleveland flash point tester [12]. Other properties analyzed were the saponification values determined by titrimetry using the methods of the Palm Oil Research Institute of Malaysia [13]. Acid value, iodine value, and peroxide value were determined by titrimetry according to FAO [14] while percentage free fatty acid (\% FFA) (as oleic) was determined by multiplying the acid value with the factor 0.503 . Thus, $\%$ $\mathrm{FFA}=0.503 \times$ acid value [15]. Analytical-grade reagents were used for all the analysis carried out.

\section{Results and Discussion}

As shown in Table 1, the oil contents of Cucumis melo (44.85\%) and Cucurbita pepo (92.50\%) show that their use for biodiesel production would be highly economical. The oils had agreeably oily smell except for those of Brachystegia eurycoma, Arachis hypogaea, and Cucurbita pepo oils that were odourless. Oils of Luffa cylidrica and Cucumis melo were very dark in colour, but the clarity of Brachystegia eurycoma, Arachis hypogaea, and Cucurbita pepo is an advantage for their use as biodiesel feedstock. Physical state of all the oils was liquid at room temperature.

Specific gravity of all the oils was in the range of 0.85 0.93 , which is close to the standard range of $0.87-0.90$ for biodiesel [16]. Density and other gravities are important parameters for diesel fuel injection systems. The values must be maintained within tolerable limits to allow optimal air to fuel ratios for complete combustion. High-density biodiesel or its blend can lead to incomplete combustion and particulate matter emissions [17]. Moisture content of the nonedible oils which were up to $8.27 \%$ was very high, far exceeding that of Arachis hypogaea oil (0.089\%) and also the stipulated ASTM standard (0.05\%). This high moisture content creates problem in transesterification, reduces shelf life, and may also cause corrosion in internal combustion engine.

As shown in Table 2, $\mathrm{pH}$ values of all the oils in the range of (5.30 to 6.07) were acidic. The ash content of the nonedible oils were of considerable quantity being up to 2\%, higher than the trace amount in Arachis hypogaea oil and exceeding the ASTM standard of 0.02 maximum. Iodine values $\left(\mathrm{g} \mathrm{I}_{2} / 100 \mathrm{~g}\right)$ were higher than the standard iodine value for biodiesel of 120 by Europe's EN 14214 specification [18] except for Luffa cylidrica and Arachis hypogaea oils. Iodine value is a measure of the unsaturation of fats and oils. High iodine value indicates high unsaturation of fats and oils [19]. Oils with iodine value above 125 are classified as drying oils; those with iodine value 110-140 are classified as semidrying oils. Those with iodine value less than 110 are considered as nondrying oil. All the oils are drying oils except Luffa cylidrica and Arachis hypogaea oil which are 
TABle 1: Physical properties of Brachystegia eurycoma, Cucurbita pepo, Luffa cylindrica, Cucumis melo, and Arachis hypogea seed oils.

\begin{tabular}{|c|c|c|c|c|c|c|c|}
\hline $\mathrm{S} / \mathrm{N}$ & Properties & Brachystegia eurycoma & Cucurbita pepo & Luffa cylidrica & Cucumis melo & Arachis hypogea oil & ASTM D6751-02 \\
\hline 1 & Oil content $(\%)$ & 14.08 & 92.50 & 12.30 & 44.85 & - & - \\
\hline 2 & Odour & Odourless & Odourless & Agreeably oily & Agreeably oily & Odourless & - \\
\hline 3 & Colour & Yellow & Yellow & Dark brown & Light brown & Yellow & - \\
\hline 4 & Specific gravity & 0.85 & 0.84 & 0.93 & 0.92 & 0.93 & - \\
\hline 5 & Moisture (\%) & 8.27 & 4.92 & 3.50 & 5.63 & 0.09 & $0.05 \% \max$ \\
\hline 6 & $\begin{array}{l}\text { Physical state at room } \\
\text { temperature }\end{array}$ & Liquid & Liquid & Liquid & Liquid & Liquid & - \\
\hline
\end{tabular}

TABle 2: Chemical properties of Brachystegia eurycoma, Cucurbita pepo, Luffa cylindrica, Cucumis melo, and Arachis hypogea seed oils.

\begin{tabular}{|c|c|c|c|c|c|c|c|}
\hline $\mathrm{S} / \mathrm{N}$ & Properties & Brachystegia eurycoma & Cucurbita pepo & Luffa cylidrica & Cucumis melo & Arachis hypogea oil & ASTM D6751-02 \\
\hline 1 & $\mathrm{pH}$ & 5.30 & 5.65 & 5.59 & 6.07 & - & - \\
\hline 2 & Ash content (\%) & 2.10 & 1.86 & 0.50 & 2.77 & Trace & $0.02 \max$ \\
\hline 3 & Iodine value (g/100 g) & 132.61 & 150.37 & 66.37 & 135.36 & 89.46 & - \\
\hline 4 & $\begin{array}{l}\text { Acid value } \\
(\mathrm{mgKOH} / \mathrm{g})\end{array}$ & 27.08 & 36.47 & 2.47 & 5.40 & 2.61 & $0.8 \max$ \\
\hline 5 & $\begin{array}{l}\text { Saponification value } \\
(\mathrm{mgKOH} / \mathrm{g})\end{array}$ & 93.27 & 162.69 & 65.92 & 112.19 & 148.67 & - \\
\hline 6 & $\begin{array}{l}\text { Peroxide value } \\
(\mathrm{meq} / \mathrm{kg})\end{array}$ & 4.36 & 5.66 & 9.37 & 9.83 & 22.25 & - \\
\hline 7 & Free fatty acid (\%) & 13.54 & 18.23 & 1.23 & 2.525 & 1.31 & - \\
\hline 8 & Flash point $\left({ }^{\circ} \mathrm{C}\right)$ & 288.00 & 312.00 & 338.00 & 298.00 & 178.00 & $130.00 \mathrm{~min}$ \\
\hline 9 & $\begin{array}{l}\text { Kinematic viscosity } \\
\left(\mathrm{mm}^{2} / \mathrm{s}\right)\end{array}$ & 0.13 & 0.70 & 0.92 & 0.81 & 32.66 & $1.90-6.00$ \\
\hline 10 & Refractive index & 0.91 & 0.73 & 0.75 & 0.71 & 1.46 & - \\
\hline
\end{tabular}

nondrying oils. Oils that are susceptible to drying are also susceptible to becoming rancid. This implies that the oil cannot be preserved for a long period of time. If used as straight vegetable oil, it is more likely to polymerize in the heat of the engine. The iodine values for the drying oils were close to iodine value of 135 for candlenut oil which can cause the lowering of pour point [20].

Acid values of the nonedible oils were also very high and exceeded the ASTM standard of $0.8 \mathrm{mgKOH} / \mathrm{g}$. They also exceeded the value for Arachis hypogaea oil except for Luffa cylidrica with $2.47 \mathrm{mgKOH} / \mathrm{g}$. Acid value measures the presence of corrosive free fatty acids and oxidation products. This is actually an important variable in considering the quality of oil because the lower the free fatty acid, the better the quality of oil. The acceptable limit for edible oils is $\leq 10$ [21]. FFA concentrations of the oils were all higher than the maximum limit of $2.0 \%$ reported for high-grade Codex Alimentarius [22] except for Luffa cylidrica and Arachis hypogaea. Vegetable oils containing high free fatty acids have significant effects on the transesterification with methanol using alkaline catalyst. It also interferes with the separation of fatty acid ester and glycerols [23]. This indicates that the oils would be better converted to biodiesel using the two-stage process of esterification and transesterification [24].

Saponification values $(\mathrm{mgKOH} / \mathrm{g})$ of the oils were about $>100$ except for Luffa cylidrica oil (65.92). Saponification value is used in checking adulteration. The saponification values were close to 148.67 but just a bit lower than 190.34 for Psophocarpus tetragonolobus seed oil [9], shea-nut oil having 195 and also that of 193.55 for jatropha oil [25]. It indicates the presence of high percentage of fatty acids in the oil [26] and therefore implies the possible tendency to soap formation and difficulties in separation of products if utilized for biodiesel production. This would also suggest that using the oils for biodiesel production would lead to very low yields in the methyl esters.

Peroxide values of the nonedible oils were in the range of $4.36-9.82 \mathrm{meq} / \mathrm{kg}$ which were far higher than that of jatropha oil seed $(1.93 \mathrm{meq} / \mathrm{kg})$ and shea-nut oil $(0.28 \mathrm{meq} / \mathrm{kg})$ but lower than that of Arachis hypogaea oil $(22.25 \mathrm{meq} / \mathrm{kg})$. The high peroxide value shows that the oil can easily go rancid and therefore has short shelf life. This shows that shea-nut oil can resist lipolytic hydrolysis and oxidative deterioration [15] and also proves the oxidative stabilities of the jatropha oil relatively [25] and therefore instability of all the oils analyzed in this study. Oils having high percentages of peroxide are unstable and grow rancid easily [27]. This indicates that if the oils are to be used for the purposes of biodiesel production, then they have to be utilized as soon as they are produced or extracted.

Flash point of the nonedible oils was well above $200^{\circ} \mathrm{C}$ exceeding 178.00 of the edible oil. They were all above the $130^{\circ} \mathrm{C}$ minimum ASTM recommended range and therefore pose no risk of fire outbreaks in case of accidents which also 
conformed to the $>100^{\circ} \mathrm{C}$ recommended flash point by SNI 04 [20]. The viscosities of the nonedible oils were in the range of 0.13 to 0.92 , being far below 32.66 of Arachis hypogaea oil. The refractive index of Arachis hypogaea oil which was 1.4631 is very close to the values reported for other seed oils, that is, 1.48 for Telfairia occidentalis seed oil, 1.47 for soybean oil, and 1.47 for corn oil [28]. Brachystegia eurycoma had the highest refractive index of 0.91 while the others were about 0.73 . This indicates that the oil is less viscous compared to most drying oils with refractive indices between 1.48 and 1.49 [29]. The refractive index of oils actually depends on their molecular weight, fatty acid chain length, degree of unsaturation, and degree of conjugation. Triacylglycerols have higher refractive indices than do their constituent free acids. Values of refractive index for different oils generally vary between 1.447 and 1.482 [30]. Also, when the biodiesel temperature is near to the cloud point, a cloudy state appears and the refractive index changes; hence, it is a significant parameter to evaluate the state of a biodiesel [31].

\section{Conclusion}

Cucurbita pepo and Cucumis melo oils had very good yields which show that they are very good and viable food stock for biodiesel production. The other oils though low in yields could be exploited for biodiesel production since they are derived from non common food sources while the byproducts emanating from their processing would be useful in firing boilers for plants or as animal feed if properly processed. The major limitations of all the oils were mostly high acid and FFA values. These high values for those parameters make them more suitable for the two-stage process of biodiesel production in order to obtain reasonable yields of the methyl esters. The conversion of these oils to biodiesel using the two-stage process will constitute a separate report.

\section{References}

[1] T. Puangsri, S. M. Abdulkarim, and H. M. Ghazali, "Properties of carica papaya L. (papaya) seed oil following extraction using solvent and aqueous enzymatic methods," Journal of Food Lipids, vol. 12, no. 1, pp. 62-76, 2005.

[2] M. V. Nagarhalli, V. M. Nandedkar, and K. C. Mohite, "Emission and performance characteristics of karanja biodiesel and its blends in a C.I. engine and it's economics," Journal of Engineering and Applied Sciences, vol. 5, pp. 52-56, 2010.

[3] S. Miladi, R. Jarraya, and M. Damak, "Lipid composition and antioxidant activities of Daucus maritimus seeds," Journal of Applied Sciences, vol. 8, no. 24, pp. 4689-4693, 2008.

[4] M. C. Ndukwu, "Determination of selected physical properties of Brachystegia eury coma seeds," Research in Agricultural Engineering, vol. 55, no. 4, pp. 165-169, 2009.

[5] I. O. Oboh and E. O. Aluyor, "Luffa cylindrica-an emerging cash crop," African Journal of Agricultural Research, vol. 4, no. 8, pp. 684-688, 2009.

[6] D. Gonzalez-Ibeas, J. Blanca, L. Donaire et al., "Analysis of the melon (Cucumis melo) small RNAome by high-throughput pyrosequencing," BMC Genomics, vol. 12, article 393, 2011.
[7] R. Rakhi and L. Rajamony, "Variability, heritability and genetic advance in landraces of culinary melon (Cucumis melo L.)," Journal of Tropical Agriculture, vol. 43, no. 1-2, pp. 79-82, 2005.

[8] A. Idouraine, E. A. Kohlhepp, and C. W. Weber, "Nutrient constituents from eight lines of naked seed squash (Cucurbita pepo L.)," Journal of Agricultural and Food Chemistry, vol. 44, no. 3, pp. 721-724, 1996.

[9] M. A. Ali, M. A. Sayeed, R. K. Roy, S. Yeasmin, and A. M. Khan, "Comparative study on characteristics of seed oils and nutritional composition of seeds from differet varieties of tobacco (Nicotiana tabacum 1.) cultivated in Bangladesh," Asian Journal of Biochemistry, vol. 3, no. 4, pp. 203-212, 2008.

[10] R. K. Singh and S. K. Padhi, "Characterization of jatropha oil for the preparation of biodiesel," Natural Product Radiance, vol. 8, no. 2, pp. 127-132, 2009.

[11] M. Manzoor, F. Anwar, T. Iqbal, and M. I. Bhanger, "Physicochemical characterization of moringa concanensis seeds and seed oil," Journal of the American Oil Chemists' Society, vol. 84, no. 5, pp. 413-419, 2007.

[12] J. Van Gerpen, "Biodiesel processing and production," Fuel Processing Technology, vol. 86, no. 10, pp. 1097-1107, 2005.

[13] Anon, Palm Oil Research Institute of Malaysia, Ministry of Primary Industries, Bangi, Malaysia, 1995.

[14] FAO, Guide to Specifications for General Notices, General Analytical Techniques, Identification Tests, Test Solutions, and other Reference Materials, vol. 5 of FAO Food and Nutrition, Rome, Italy, 1991.

[15] I. R. Ejilah and A. A. Asere, "Tested performance parameters of Transesterified sheanut oil and diesel fuel blends in compression ignition engines," in Proceedings of the National Solar Energy Forum in Makurdi, Nigeria, pp. 1-14, 2009.

[16] P. M. Ejikeme, C. A. C. Egbonu, I. D. Anyaogu, and V. C. Eze, "Fatty acid methy esters of melon seed oil: characterization for potential diesel fuel application," in Chemical Society of Nigeria, Enugu Chapter, Coal City Chemistry Conference proceedings, pp. 37-41, 2008.

[17] A. Galadima, Z. N. Garba, and B. M. Ibrahim, "Homogeneous and heterogeneous transesterification of groundnut oil for synthesizing methyl biodiesel," International Journal of Pure and Applied Sciences, vol. 2, pp. 138-144, 2008.

[18] S. M. Son, K. Kusakabe, and G. Guan, "Biodiesel synthesis and properties from sunflower and waste cooking oils using $\mathrm{CaO}$ catalyst under reflux conditions," Journal of applied Sciences, vol. 10, no. 4, pp. 3191-3198, 2010.

[19] G. Knothe, "Structure indices in FA chemistry. How relevant is the iodine value?" Journal of the American Oil Chemists' Society, vol. 79, no. 9, pp. 847-854, 2002.

[20] H. Sulistyo, I. M. Suardjaja, and S. S. Rahayu, "Transesterification of candlenut oil with ethanol to biodiesel," in Proceeding on Regional Symposium on Chemical Engineering (RSCE '06), Singapore, December 2006.

[21] A. E. Balley, Industrial Oil and Fat Product, John WileyInterscience, New York, NY, USA, 3rd edition, 1982.

[22] "Codex Alimentairus Commission," Graisses et huiles vegetables, division 11. Version Abregee FAO/WHO Codex Stan 1993, 20-1981, 23-1981, 1993.

[23] F. Ma and M. A. Hanna, "Biodiesel production: a review," Bioresource Technology, vol. 70, no. 1, pp. 1-15, 1999.

[24] A. Kac, "The foolproof way to make biodiesel: free fatty acid to ester conversion," 2001, http://journeytoforever.org/biodiesel_aleksnew.html.

[25] E. Akbar, Z. Yaakob, S. K. Kamarudin, M. Ismail, and J. Salimon, "Characteristic and composition of Jatropha curcas 
oil seed from Malaysia and its potential as biodiesel feedstock feedstock," European Journal of Scientific Research, vol. 29, no. 3, pp. 396-403, 2009.

[26] O. O. Omolara and O. O. Dosumu, "Preliminary Studies on the effect of processing methods on the quality of three commonly consumed marine fishes in Nigeria," Biokemistri, vol. 21, no. 1, pp. 1-7, 2009.

[27] J. M. Nzikou, M. Mvoula-Tsieri, L. Matos et al., "Solanum nigrum L. seeds as an alternative source of edible lipids and nutriment in Congo Brazzaville," Journal of Applied Sciences, vol. 7, no. 8, pp. 1107-1115, 2007.

[28] V. A. Sodeke, "Extraction of oil from water melon seed and analysis," Quarterly Research Service, 2005.

[29] O. M. Oluba, Y. R. Ogunlowo, G. C. Ojieh, K. E. Adebisi, G. O. Eidangbe, and I. O. Isiosio, "Physicochemical properties and fatty acid composition of Citrullus lanatus (Egusi Melon) seed oil," Journal of Biological Sciences, vol. 8, no. 4, pp. 814-817, 2008.

[30] F. Shahidi, Quality Assurance of Fats and Oils. Bailey's Industrial Oil and Fat Products, vol. 6 of Edited by F. Shahidi, John Wiley \& Sons, 6th edition, 2005.

[31] A. R. Sadrolhosseini, M. M. Moksin, H. L. L. Nang, M. Norozi, M. M. W. Yunus, and A. Zakaria, "Physical properties of normal grade biodiesel and winter grade biodiesel," International Journal of Molecular Sciences, vol. 12, no. 4, pp. 2100-2111, 2011. 

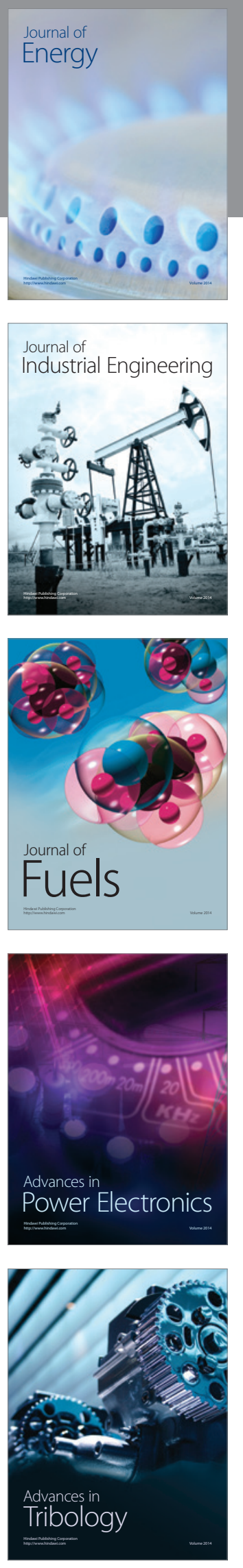
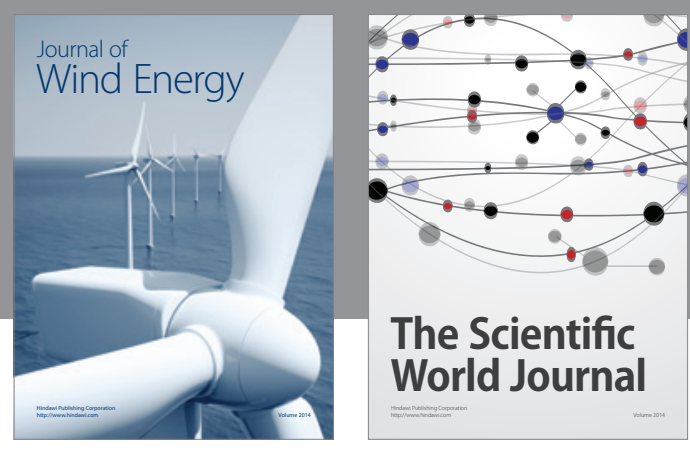

The Scientific World Journal

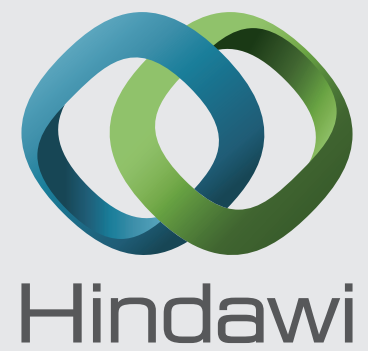

Submit your manuscripts at http://www.hindawi.com
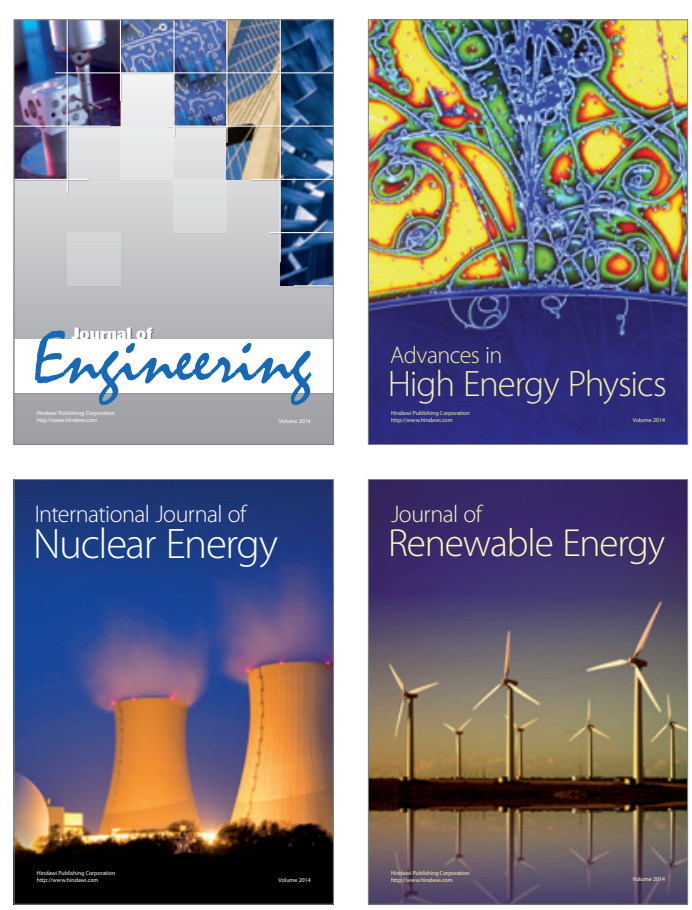

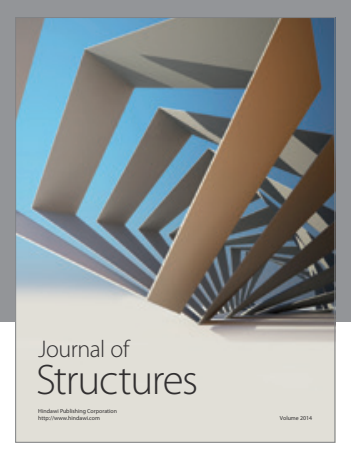

Rotating
Mechinery
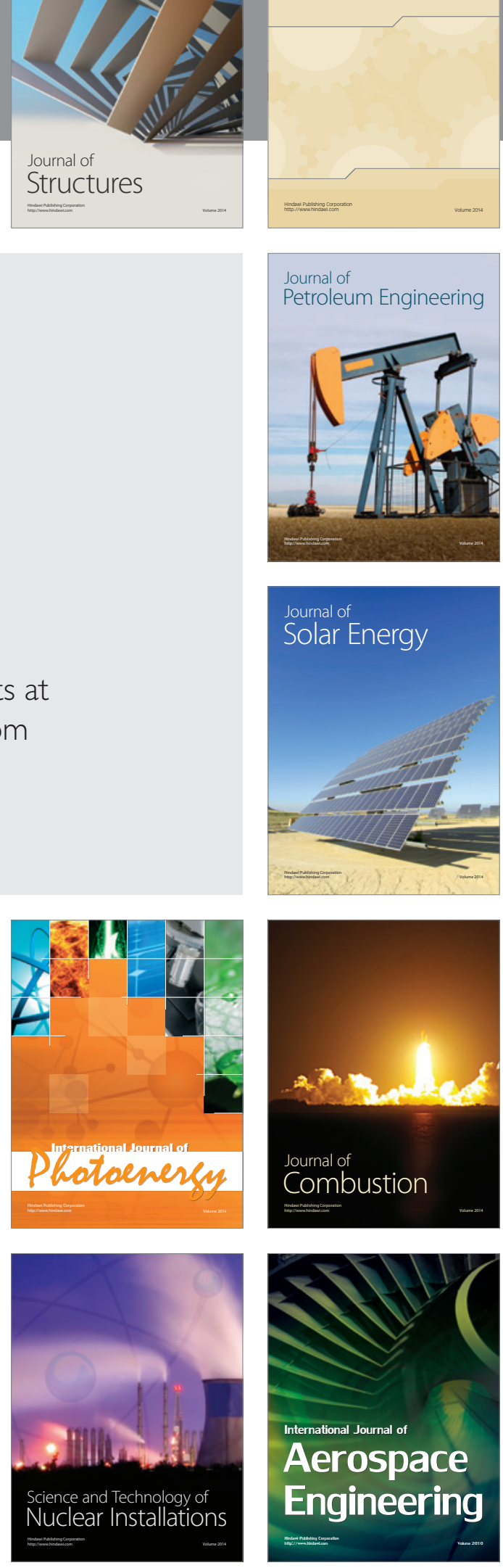